\title{
Influence of Machining Parameters on Fatigue Endurance Limit of AISI 4140 Steel
}

Pontifícia Universidade Católica de Minas Gerais 30535-610 Teixeira de Freitas, BA, Brazil

\section{Wisley Falco Sales}

wisley@ffassis.edu.br

Faculdade do Sul da Bahia - FASB

30535-610 Teixeira de Freitas, BA, Brazil

Ernani S. Palma

palma@pucminas.br

Pontifícia Universidade Católica de Minas Gerais 30535-610 Teixeira de Freitas, BA, Brazil
The general purpose of this research is to study the influence of commercial machining parameters on fatigue limits of steels. Specifically in this work, the influence of cutting speeds, depth of cut, feed rate and residual stresses of turned surfaces of AISI 4140 steel specimens on fatigue strength were analyzed. In some specimens, the residual stress was eliminated by heat treatment. The fatigue experiments were carried out at room temperature, applying a cyclical frequency of $58 \mathrm{~Hz}$, with mean stress equal to zero $(R=-1)$, on a rotating-bending fatigue testing machine of the constant bending moment type. It was used the staircase (or up-and-down) method to determine the fatigue limit of the specimens.

Keywords: fatigue limit, fatigue damage, machining parameters, surface roughness, surface integrity

\section{Introduction}

Components of machines, vehicles and structures are frequently subjected to cyclic loads, which in some cases may lead to their failure due to fatigue. Fatigue cracks in these components usually may be initiated in geometrical features, which cause local stress concentrations, in most cases at the surface. Thus, it is well known that the fatigue life of a machine component depends strongly on its surface layer condition. Fatigue crack nucleation and propagation, in most cases, can be attributed to surface integrity, which includes surface roughness, structure and stress conditions of the surface layer. The importance of surface integrity increases with increasing loads, temperature and frequency. This becomes critical for high strength steels, which are more sensitive to stress concentration.

The surface layer is determined by manufacturing processes, and mainly, by finishing treatments. Machining is a competitive alternative process for producing a wide range of mechanical components, such as gears, cams, shafts, axles and others. The process of machining steel is complex and the surface generated is influenced by several variables: steel properties (elastic and plastic deformations), tool material and geometry, vibration of cutting tool, cutting speed, feed, depth of cut, lubricant, etc. Besides, previous works have shown that in the machined surface of metals a damage region is produced that is different from the bulk of the material (Benados and Vosniakos, 2003, Bailey, Jeelani and Becker, 1976 and Zahavi and Torbilo, 1996). During machining, the surface layer is subjected to elastic-plastic deformation and heating, which result in structural changes, strain hardening and residual stresses, while irregularities may appear, creating surface roughness.

The influence of cutting parameters (cutting speed, feed rate and depth of cut) on surface quality, and consequently on roughness surface, is well studied. A large number of analytical and experimental studies have been conducted on surface roughness of steels in machining operations. These research developments have been performed with the objective of optimising the cutting conditions to obtain surface finish (Trent and Wright, 2000 and Yang and Tarng, 1998).

Darvim (2001) studied the influence of cutting conditions on the surface finishing obtained by turning. According to this paper, the cutting speed had the greatest influence on the roughness followed

Paper accepted January, 2008. Technical Editor: Anselmo E. Diniz. by the feed rate. The depth of cut had no significant influence on the roughness. Similar results were found by Feng (2001), that also observed that in addition to feed rate, nose radius, work material and speeds, the rake angle has a significant influence on the surface roughness.

Abouelatta and Mádl (2001) showed the possibility of predicting roughness parameters of carbon steels based on cutting parameters and tool vibrations in a turning machine. The results obtained are fairly accurate and convenient for predicting roughness parameters. The maximum height roughness parameter $\left(R_{t}\right)$ depended greatly on the rotational cutting speed and work-piece diameter.

The surface integrity in finishing hard turning of case-hardened steels was analyzed by Rech and Moisan (2003). These authors observed that the CLA average roughness $\left(R_{a}\right)$ increases with both, cutting speed and feed rate, but the latter is the main parameter that influences the surface roughness compared with the influence of cutting speed.

All above listed papers concluded that surface roughness parameters of steels increase with increasing feed rate but decrease with increasing the cutting speed and the depth of cut, respectively. For the majority of these authors, the feed rate is the main influencing cutting parameter on surface roughness of steels. Besides, the vibratory response of a machine tool system is also important in the development of the surface roughness (Benardos and Vosniakos, 2003, Thomas and Beauchamp, 2003 and Jang and Seireg, 1989).A comprehensive review of published data, which addresses the effect of machining and surface integrity on fatigue life has been made by Novovic et al. (2004). According to these authors, there is some disagreement in the literature about the influence of surface roughness on fatigue life. In most cases, it has been reported that fatigue life increases with decreasing surface roughness. This effect diminishes for $R_{a} \leq 0.1 \mu \mathrm{m}$. However, for roughness parameter $\left(R_{a}\right)$ between 2.5 and $5 \mu \mathrm{m}$, Koster (1991) has found that the residual stress is the most important factor on the fatigue life of structural alloys. This effect decreases with an increase in temperature due to the relaxation of residual stress. Similar results were found by El-Helieby and co-workers (apud Novovic et al. (2004)).

The effect of cutting speed and tool rake face angle on the fatigue life of 2024-T351 aluminium alloy was analyzed by Jeelani and Musial (1984). Specimens of these materials were machined at cutting speeds between 0.5 and $1.5 \mathrm{~ms}^{-1}$ with tool angles in the range between 10 and $30^{\circ}$. The fatigue life of the machined specimens was found to increase with increasing cutting speed or 
tool rake angle. Besides, the fatigue life of the specimens machined at higher cutting speeds was higher than that of the virgin material (polished), due to the presence of compressive residual stresses.

The fatigue strengths of machined and as-cast surfaces of ferritic SG iron have been compared by Starkey and Irving (1982). The endurance of machined specimens was found to be higher than that of as-cast surfaces. Micro pores initiated failure in the machined specimens, whereas surface irregularities or dross defects initiated cracks from the as-cast surface.

Taylor and Clancy (1991) have compared the fatigue limit of the EN 19 steel (equivalent to AISI 4140), using four types of machined surfaces produced by polishing, grinding, milling and shaping. The residual stress was eliminated by heat treatment. They found that fatigue limit of ground surfaces decreased when compared to polished specimens, that is, the fatigue limit decreased with increasing surface roughness. However, a comparison of the fatigue limits of the specimens with ground surfaces with those of milled surface specimens showed an opposite tendency, that is, an increasing of fatigue limit with increasing surface roughness. Besides, there was not observed difference between fatigue limits of the polished and fine milled specimens, even though surface roughness values were quite different.

The effects of surface roughness on cracking initiation and S-N curves of a Ni-Cr-Mo steel were studied by Itoga et al. (2003). Surface roughness was the most important influencing factor in short life regime, and the fatigue life was found to decrease with increasing surface roughness. On the contrary, in long life regime, surface roughness exerted no influence on fatigue life, because cracks nucleated at inclusions and grew inside the specimens.

Arola and Williams (2002) found that the high-cycle fatigue life of machined specimens of AISI 4130 steel is surface-texture dependent, and that the fatigue strength decreased with an increase in surface roughness from 2 to $6 \mu \mathrm{m}$. On the other hand, an increase in fatigue life occurred with increasing surface roughness under low-cycle fatigue. It was also found that the notch sensitivity of these machined specimens did not change significantly with surface roughness.

The effects of surface roughness, work-hardened layer and humidity on S-N curves of high strength AISI 4340 steel was studied by Nakajima et al. (2003). Buff-finished and electropolished specimens with two different surface conditions were prepared. Fatigue lives were longer in the buff-finished than in the electro-polished specimens, due to the presence of a work-hardened layer.

Some studies of deformation of polycrystals show that the surface roughness increases with plastic strain (Becker, 1998 and Yue, 2005). Under fatigue loading, it was found that the surface roughness increased with fatigue life, and the deformation is localized in some specific places, where micro-cracks are nucleated (Yue, 2005 ).

As shown, the importance of both surface roughness and integrity is well recognised, with many experimental and analytical models relating these characteristics with fatigue life. However, there are only few results in literature that show the influence of machining cutting parameters on fatigue life of commercial steels. In general more attention is given on the influence of grinding on fatigue strength. However, in these days materials can be machined and finished with newly developed tools, eliminating the need for other finishing operations. Thus, it is necessary to know the relationship between fatigue parameters and cutting operations. In the present study, the influence of cutting speed, depth of cut and feed rate on the fatigue endurance of turned specimens of commercial AISI 4140 steel is analyzed.

\section{Nomenclature}

$$
\begin{aligned}
& a_{p}=\text { deph of cut }, \mathrm{mm} \\
& f \quad=\text { feed rate, } \mathrm{mm} / \mathrm{rev} \\
& R_{a}=\text { CLA, average roughness, } \mu \mathrm{m} \\
& R_{q}=\text { root mean square, } \mu \mathrm{m} \\
& R_{t}=\text { maximum height roughness parameter, } \mu \mathrm{m} \\
& v_{c}=\text { cutting speed, } \mathrm{m} / \mathrm{min}
\end{aligned}
$$

\section{Experimental Procedure}

In this investigation the AISI 4140 steel was used as the work material whose chemical composition (wt\%) is given in Table 1. The microstructure of this steel is comprised of ferrite and perlite. This material was supplied as laminated cylindrical bars about 3,000 $\mathrm{mm}$ long with a diameter of $16.88 \mathrm{~mm}$ (5/8 in).

Table 1. Chemical composition of the AISI 4140 steel.

\begin{tabular}{ccccccc}
\hline Element & $\mathrm{C}$ & $\mathrm{Mn}$ & $\mathrm{Si}$ & $\mathrm{Cr}$ & $\mathrm{Mo}$ & $\mathrm{Fe}$ \\
\hline $\mathrm{wt} \%$ & 0,40 & 0,88 & 0,28 & 0,95 & 0,20 & balance \\
\hline
\end{tabular}

As-received the material was normalized. After heat treatment, fatigue specimens were turned to the configuration shown in Fig. 1.

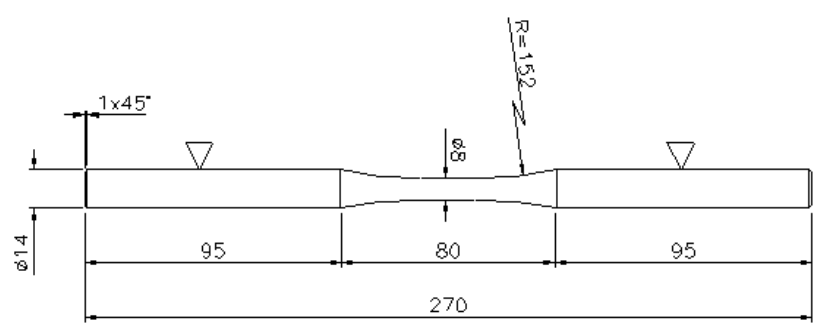

Figure 1. Test specimens - Dimensions in $\mathrm{mm}$.

The as-received bars were turned with the cutting parameters shown in Table 2. All these conditions are used in finishing turning operations. They were chosen in order to have specimens with three different feed rates (group 2, conditions 2.1 to 2.3), three different depths of cut (group 1, conditions 1.1, 1.2 and 2.1), and three different cutting speeds (group 3, conditions 3.1, 3.2 and 2.1). Thus, each group has two constants and only one variable cutting parameter. These specimens will be designated according to their condition number hereafter (Ex.: condition 1.1, etc). The turning process was carried out using a CNC lathe model Romi Centur 30D with emulsion as a cutting fluid (Esso, specification Kutwell 40) at concentration of $6 \%$. The selected cutting tool was cemented carbide (WC+Co+TiC+TaC), specification of DCMT 11 T $304-$ PM05, WAM-20 and coated by TiN. The used tool geometry was as follows: rake angle $\gamma_{0}=6^{0}$, clearance angle $\alpha_{0}=5^{0}$, approach angle $\chi_{\mathrm{r}}=60^{\circ}$ and inclination angle $\lambda_{\mathrm{s}}=0^{0}$. The tool-holder used for machining the specimens is PDJCR2020. Both, cutting tool and tool-holder were produced by Walter do Brasil. All tests were carried out with fresh edges (without wear) on cutting tools. An optical microscope was used to control the cutting tool wear. 
Table 2.Cutting conditions of the as-received steel bars.

\begin{tabular}{|c|c|c|c|c|c|c|}
\hline \multirow{2}{*}{\multicolumn{2}{|c|}{$\begin{array}{c}\text { Group 1 } \\
\mathrm{v}_{\mathrm{c}}=60 \mathrm{~m} / \mathrm{min} \\
\mathrm{f}=0.12 \mathrm{~mm} / \mathrm{rev}\end{array}$}} & \multirow{2}{*}{\multicolumn{3}{|c|}{$\begin{array}{c}\text { Group 2 } \\
\mathrm{v}_{\mathrm{c}}=60 \mathrm{~m} / \mathrm{min} \\
\mathrm{a}_{\mathrm{p}}=1.2 \mathrm{~mm}\end{array}$}} & \multirow{2}{*}{\multicolumn{2}{|c|}{$\begin{array}{c}\text { Group 3 } \\
\mathrm{f}=0.12 \mathrm{~mm} / \mathrm{rev} \\
\mathrm{a}_{\mathrm{p}}=1.2 \mathrm{~mm}\end{array}$}} \\
\hline & & & & & & \\
\hline Condition 1.1 & Condition 1.2 & Condition 2.1 & Condition 2.2 & Condition 2.3 & Condition 3.1 & Condition 3.2 \\
\hline $\mathrm{a}_{\mathrm{p}}=0.4 \mathrm{~mm}$ & $\mathrm{a}_{\mathrm{p}}=2.0 \mathrm{~mm}$ & $\mathrm{f}=0.12 \mathrm{~mm} / \mathrm{rev}$ & $\mathrm{f}=0.18 \mathrm{~mm} / \mathrm{rev}$ & $\mathrm{f}=0.25 \mathrm{~mm} / \mathrm{rev}$ & $\mathrm{v}_{\mathrm{c}}=15 \mathrm{~m} / \mathrm{min}$ & $\mathrm{v}_{\mathrm{c}}=100 \mathrm{~m} / \mathrm{min}$ \\
\hline
\end{tabular}

After turning of another fifty specimens, their surfaces were finished by grinding and polishing to achieve a surface finish of $R_{a}$ $=0,15 \pm 0,01 \mu \mathrm{m}$ in the gauge length. These specimens are designated as polished hereafter. They were used to generate reference mechanical properties.

\section{Surface Roughness Measurements}

After turning with each combination of cutting parameters, the surface roughness was measured. A surface evaluation system (Surftest SJ-400 perfilometer, Mitutoyo) was used in the surface roughness measurements over the turning surfaces. The surface perfilometer was set for a $0.8 \mathrm{~mm}$ cut-off length. Surface roughness was evaluated using the arithmetic mean value $\left(\mathrm{R}_{\mathrm{a}}\right)$, the Root Mean Square $\left(R_{q}\right)$, and the peak to valley height or maximum height roughness parameter $\left(\mathrm{R}_{\mathrm{t}}\right)$ over the gauge length of $80 \mathrm{~mm}$ (Fig. 1) of all specimens. The surface roughness measurements on each specimen were repeated four times. The average values of all specimens of each condition have been used as a data point.

\section{Tensile and Fatigue Tests}

Tensile tests were performed on a tensile testing machine (INSTRON) with head speed of $200 \mathrm{~mm} / \mathrm{min}$, at room temperature $\left(22{ }^{\circ} \mathrm{C}\right)$ according to ASTM E-23. Vickers hardness tests were performed according to ASTM E-92.

Fatigue tests were carried out at room temperature, applying a cyclical frequency of $58 \mathrm{~Hz}$, with mean stress equal to zero $(\mathrm{R}=-1)$, on a rotating-bending fatigue testing machine of the constant bending moment type. The specimens are subjected to a constant bending moment along its gauge length $(80 \mathrm{~mm}$ according to Fig. 1) between the inboard bearings. The specimens were cooled to maintain the constant temperature of $23 \pm 2{ }^{\circ} \mathrm{C}$ during the test.

The staircase or up-and-down method was used to determine the fatigue limit of the specimens (Collins, 1993 and Lee et al., 2005). 15 specimens of each condition were used for determining the fatigue limit, as follow: The first specimen was tested at a stress level higher than the estimated fatigue limit until it either was failed or was ran out. As run out criterium it was chosen $2 \times 10^{6}$ cycles. If the specimen failed before reaching $2 \times 10^{6}$ cycles, the stress level was decreased by a pre-selected increment and the second specimen was tested at this new lower stress level. If the first specimen ran out, the stress level was increased by the pre-selected increment and the second specimen was tested at this new higher stress level. The test was continued in this sequence, with each succeeding specimen being tested at a stress level that was above or below its predecessor. The obtained experimental data were statistically analyzed according to Lee et al. (2005), using the Dixon-Mood method (Lee et al., 2005 and Lin et al., 2001).

\section{Experimental Results: Preliminary Results}

The monotonic mechanical properties of SAE 4140 steel are summarized in Table 3.

\section{Table 3. Mechanical properties of AISI 4140 steel.}

\begin{tabular}{ccc}
\hline $\begin{array}{c}\text { Ultimate Tensile } \\
\text { Strength }-\sigma_{\text {UTS }}(\mathrm{MPa})\end{array}$ & $\begin{array}{c}0,2 \text { Yield Strength } \\
\sigma_{0.2}(\mathrm{MPa})\end{array}$ & $\begin{array}{c}\text { Hardness } \\
(\mathrm{HV})\end{array}$ \\
\hline $964.95 \pm 21.84$ & $758.05 \pm 31.55$ & $249 \pm 30$ \\
\hline
\end{tabular}

As shown in Fig. 2, the surface roughness decreases with increasing depth of cut. At depth of cut of $0.4 \mathrm{~mm}$, the roughness parameters are very high, decreasing considerably with increasing depth of cut to $1.2 \mathrm{~mm}$. Further increase in depth of cut to $2.0 \mathrm{~mm}$ caused no significant change in the surface roughness of the steel.

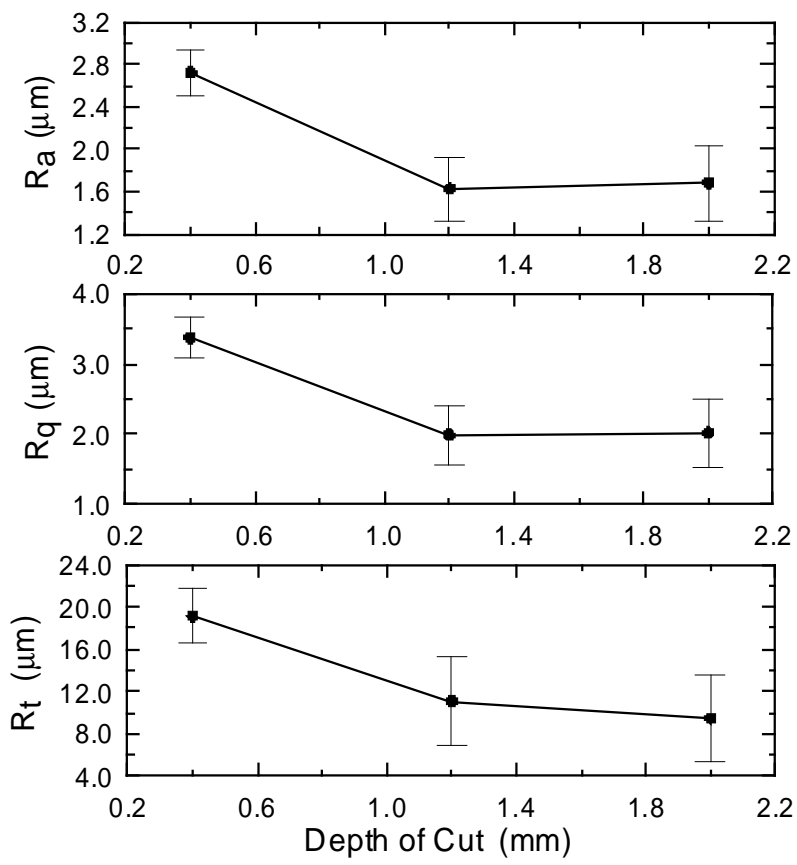

Figure 2. Influence of depth of cut on surface roughness parameters.

An increase of feed rate causes an almost linear increase of all measured surface roughness parameters, as shown in Fig. 3. 

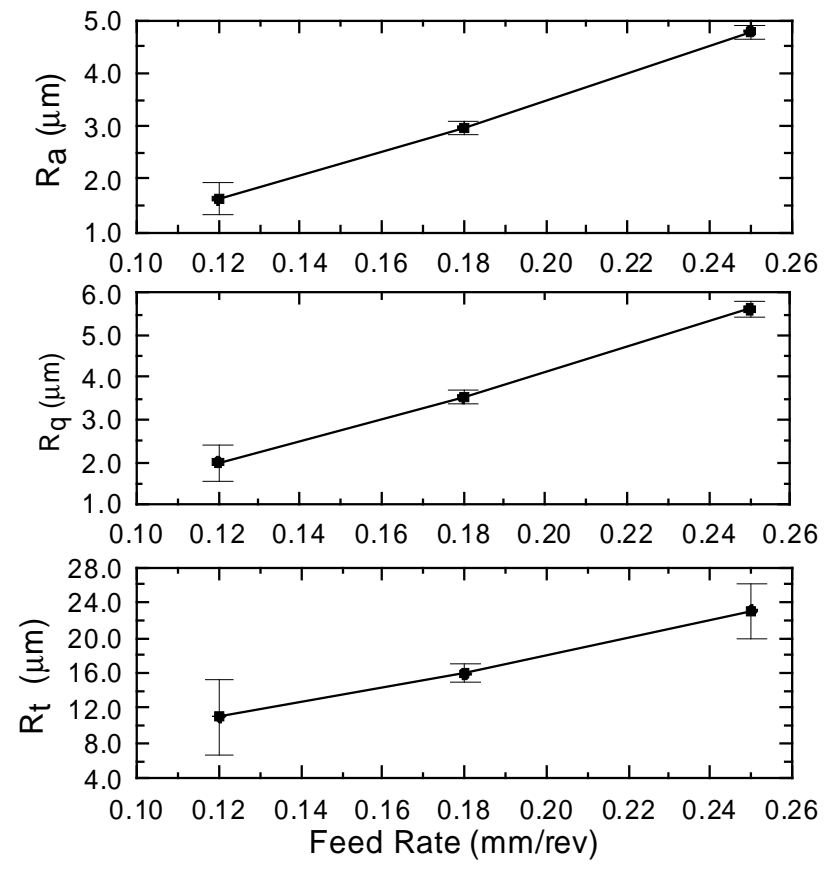

Figure 3. Influence of feed rate on surface roughness parameters.

As shown in Fig. 4, the effect of cutting speed on the surface roughness parameters is similar to those in Fig. 2, that is, surface roughness decrease initially rapidly, then slowly, with increasing cutting speed. At low cutting speed, the roughness parameters are very high, decreasing considerably with increasing cutting speed from 15 to $60 \mathrm{~mm} / \mathrm{min}$. The decrease in the surface roughness is less significant at higher cutting speeds.
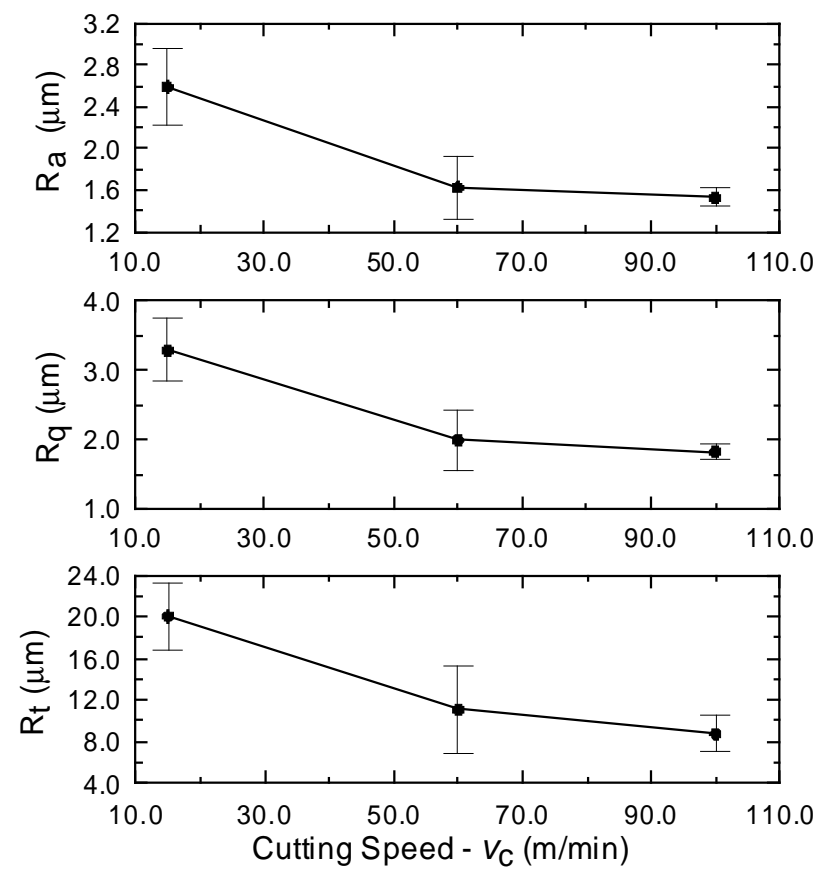

Figure 4. Influence of cutting speed on surface roughness parameters.

All these results here observed are in accordance with those addressed in the literature (Benardos and Vosniakos, 2003, Bailey, Jeelani and Becker, 1976 and Abouelatta and Mádl, 2001). The variation of all measured roughness surface parameters is summarized in Table 4. It can be observed that the greatest changing of average surface roughness parameters $\left(R_{a}\right.$ and $\left.R_{q}\right)$ is caused by the feed rate, when compared with cutting speed and depth of cut. This is also in accordance with some previous published papers (Abouelatta and Mádl, 2001 and Thomas et al., 2003). The change of maximum height roughness parameter $\left(R_{t}\right)$ is similar for all conditions.

Table 4. Changing of the surface roughness parameters with cutting parameters.

\begin{tabular}{cccc}
\hline & \multicolumn{3}{c}{ Changing of surface roughness } \\
& $\mathrm{R}_{\mathrm{a}}$ & $\mathrm{R}_{\mathrm{q}}$ & $\mathrm{R}_{\mathrm{t}}$ \\
\cline { 2 - 4 } & 66 & 65 & 52 \\
\hline Feed rate (f) & -41 & -45 & -56 \\
\hline Cutting speed $\left(\mathrm{v}_{\mathrm{c}}\right)$ & -38 & -40 & -50 \\
\hline Depth of cut $\left(\mathrm{a}_{\mathrm{p}}\right)$ & -38 ) \\
\hline
\end{tabular}

\section{Fatigue Experiments}

The fatigue limits of the specimens machined according to the conditions showed in Table 2 were determined using the stair case method. Since all experiments are similar, in this paper it will be showed only the results of these tests for one condition of each group of the Table 2. The experimental tests of the specimens machined according to condition 1.1 were performed with alternating stress varying from 323.15 to $381.09 \mathrm{MPa}$ (Fig. 5). The fatigue limit of this condition was found to be equal to $287.96 \pm$ $21.54 \mathrm{MPa}$.

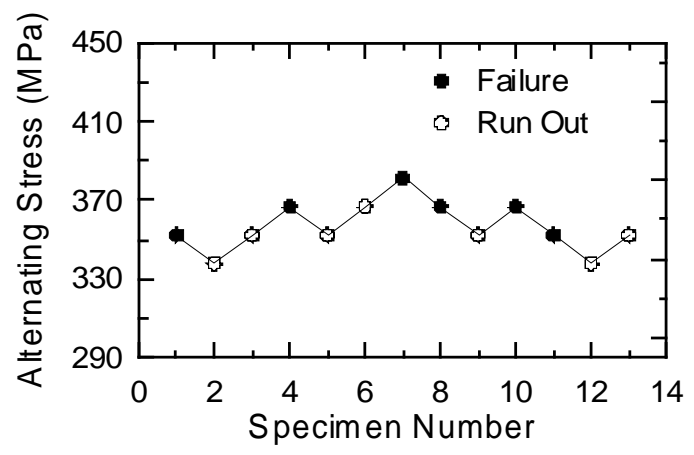

Figure 5. Stair case fatigue test - Condition 1.1.

The stair case test of the specimens of the condition 2.1 with alternating stress varying from 395.97 to $424.54 \mathrm{MPa}$ is showed in Fig. 6. The fatigue limit for this condition 2.1 was found to be equal to $366.84 \pm 16.32 \mathrm{MPa}$.

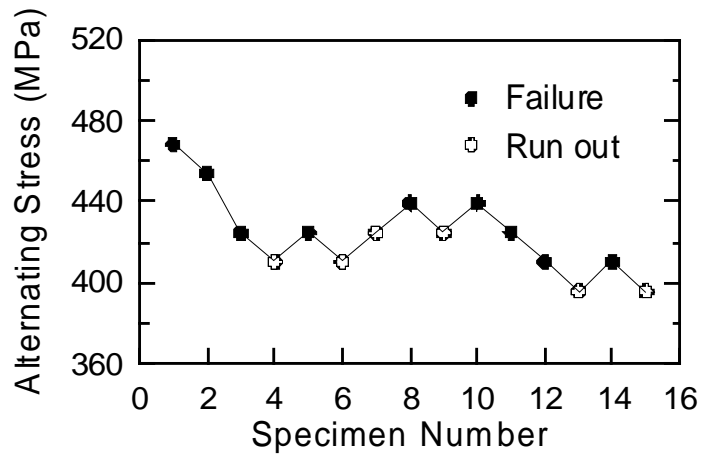

Figure 6. Stair case fatigue test - Condition 2.1. 
The stair case test of the specimens of the condition 3.1 was performed using alternating stresses from 366.66 to $410.06 \mathrm{MPa}$, as shown in Fig. 7. The fatigue limit of this condition 3.1 was equal to $341.10 \pm 13.72 \mathrm{MPa}$.

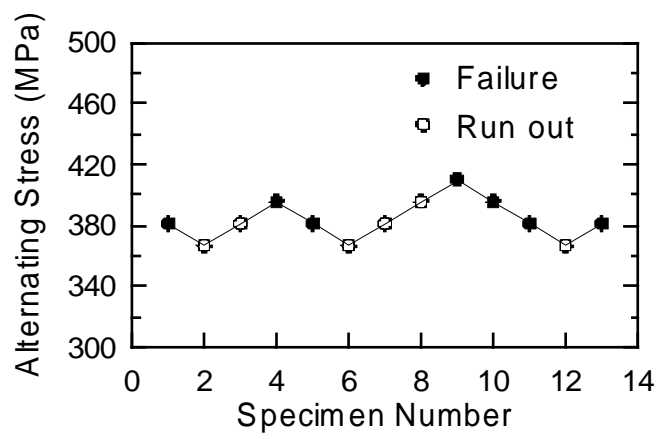

Figure 7. Stair case fatigue test - Condition 3.1.

The influence of depth of cut $\left(a_{p}\right)$ on fatigue limit is shown in Fig. 8. The fatigue limit of AISI 4140 steel increases almost $18 \%$ with increasing depth of cut from 0.4 to $1.2 \mathrm{~mm}$. Further increase in depth of cut to $2.0 \mathrm{~mm}$ has no pronounced influence on the average fatigue limit of this steel. However, the dispersion of the fatigue limit increases with increasing depth of cut. The influence of depth of cut on fatigue limit is similar to those observed in Fig. 2.

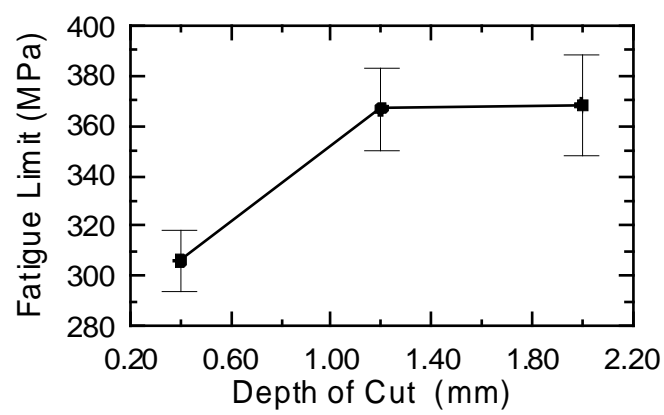

Figure 8. Influence of depth of cut on fatigue limit.

The fatigue limit of AISI 4140 steel increases almost linear with increasing cutting speed $\left(\mathrm{v}_{\mathrm{c}}\right)$, as shown in the Fig. 9. This result was expected, since increasing cutting speed leads to smaller roughness values. Besides, the cutting speed had no influence on the dispersion of the fatigue limit.

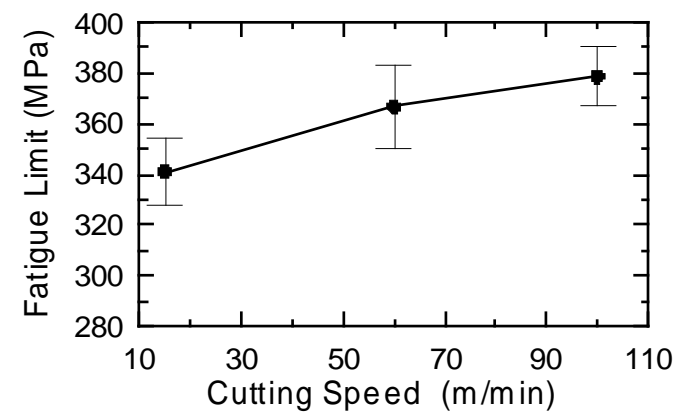

Figure 9 . Influence of cutting speed on fatigue limit.

The fatigue limit of the AISI 4140 steel is only slightly influenced when the feed rate (f) is increased from 0.12 to 0.18 $\mathrm{mm} / \mathrm{rev}$, as shown in Fig. 10. A sharp decrease in fatigue limit is observed when the feed rate is further increased to $0.25 \mathrm{~mm} / \mathrm{rev}$. It was previously shown that surface roughness increased almost linear with increasing feed rate. Thus, it was expected a similar behavior between fatigue limit and feed rate. It becomes evident that fatigue limit is determined not only by roughness values. Residual stresses originated by machining are also important.

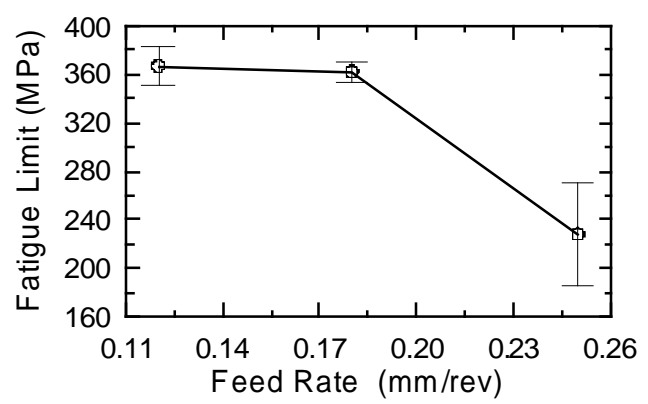

Figure 10. Influence of feed rate on fatigue limit.

The variation of all measured fatigue limits with cutting parameters is summarized in Table 5. The most influent parameter on fatigue limit is the feed rate. This is in accordance with the surface roughness results (Table 4). However, the changes of fatigue limits with cutting parameters are quite lower than that observed previously by the roughness parameters. Thus, only the roughness parameters can not explain the changes of fatigue limits of this steel. The fatigue endurance of machined component depends strongly on its surface layer condition. During the machining, the surface layer is subjected to several phenomena, which result in structural changes, strain hardening and residual stresses, while irregularities may appear, creating surface roughness. The fatigue limit is determined by all these parameters.

Table 5. Changing of fatigue limit with cutting parameters.

\begin{tabular}{ll}
\hline & Changing of fatigue limit $(\%)$ \\
\hline Feed rate $(\mathrm{f})$ & -38 \\
\hline Cutting speed $\left(\mathrm{v}_{\mathrm{c}}\right)$ & 12 \\
\hline Depth of cut $\left(\mathrm{a}_{\mathrm{p}}\right)$ & 18 \\
\hline
\end{tabular}

To analyze the influence of residual stresses on fatigue limit, several specimens of condition 2.3 (with the greatest roughness values) were submitted to a stress relief heat treatment. After that, these specimens were submitted to fatigue tests, with identical test parameters as before. As shown in Fig. 11, the fatigue limit of these heat treated specimens increased almost $30 \%$ in comparison with fatigue limit of non heat treated specimens. Besides, the influence of feed rate on fatigue limit became almost linear, similar to the results previously shown between feed rate and roughness values. Finally, it also can be observed that the dispersion of the heat treated specimens is smaller than those non heat treated.

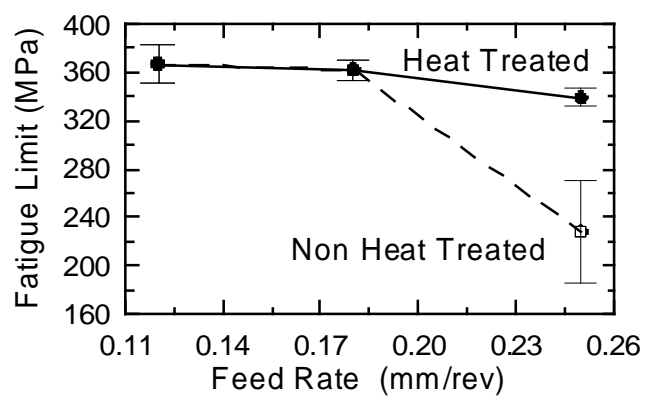

Figure 11. Influence of feed rate and residual stress relief on fatigue limit. 
The influence of residual stresses on fatigue limit of polished (grounded) specimens, with surface roughness $R_{a}=0,15 \pm 0,01 \mu \mathrm{m}$, was analyzed. The stair case tests of specimens of this condition just grounded (without relief stress) and with stress relief heat treatment are shown in figures 12 and 13, respectively. The fatigue limits of these conditions were equal to $395.98 \pm 7.68 \mathrm{MPa}$ and $305.50 \pm 12.17$ $\mathrm{MPa}$ for specimens without relief stress and with thermal treatment, respectively. Thus, the stress relief heat treatment caused a decrease of almost $23 \%$ of the fatigue limit of the annealed specimens in comparison with those of non heat-treated specimens.

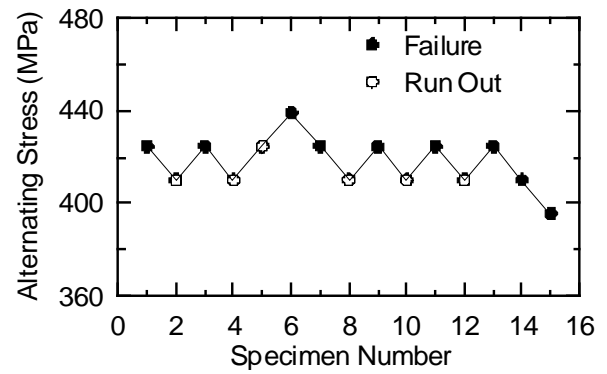

Figure 12. Stair case fatigue test - Polished specimens without stress relief.

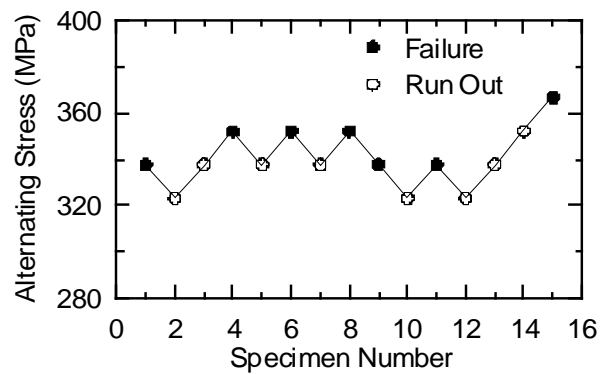

Figure 13. Stair case fatigue test - Polished specimens with stress relief.

The influence of roughness surface on fatigue limits of all machined and polished specimens is summarized in Fig. 14. The fatigue limit decreases almost linear with increasing roughness surface. This tendency is not obeyed when the specimens without residual stress (heat treated) is included. Besides, the highest value of fatigue limit was reached in the polished specimens, without relief stress. However, relief stress heat treatment in machined specimens can substantially raise their fatigue endurances. If machined specimens with better initial fatigue limit than that previous utilized (Fig. 11) would stress relief heat treated, a higher fatigue limit could be reached. Thus, it could be cheaper to produce components using only commercial machining parameters and stress relief heat treatment, than polished specimens.

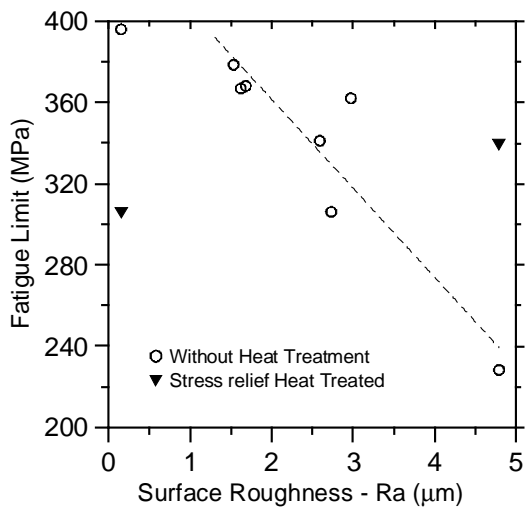

Figure 14. Summary of fatigue limits of all analyzed specimens.
The heat treatment after mechanical processing excluded the effects of residual stresses and cold work of the machined surface of the specimens. Two opposite effects on fatigue limit of the tested specimens were caused by the residual relief stress heat treatment: An increase of fatigue limit in specimens with high roughness parameters $\left(\mathrm{R}_{\mathrm{a}} \approx 4,8 \mu \mathrm{m}\right)$, and a decrease in the polished specimens $\left(\mathrm{R}_{\mathrm{a}} \approx 0,15 \mu \mathrm{m}\right)$. The surface layer condition is determined by an interaction between strain hardening, residual stresses and roughness values. The specimen types showed distinct decrease of surface hardness values after heat treatment, as shown in Table 6. Considering that the heat treatment was exactly the same for all specimens, it is evident that the interaction between residual stresses and roughness explain the changes of fatigue limits. In specimens with high surface roughness parameters, the residual stresses are more harmful than those polished. Moreover, according to Sasahara (2005) and others authors (Novovic et al., 2004, Koster, 1991, Jeelani and Musial, 1984 and Starkey and Irving, 1982), residual tensile stresses are introduced in the material with cutting conditions similar as those used in this work (condition 2.3). Actually, the strain-hardened surface layer blocks propagation of fatigue cracks and resists creation of the new ones. Such a layer may outweigh negative effects of surface roughness. However, since the roughness parameter values are very high for machined specimens (condition 2.3), the notch effect is more effective than that of strain hardening. The maximum notch stress is very high in these specimens. The heat treatment eliminated both, strain hardening and residual stress. The reduction of residual stress leads to a decrease of maximum notch (local) stress that is more effective that the decrease of fatigue limit caused by the surface softening. These findings are in according with the results reported by $\mathrm{Du}$ et al. (2004). In the polished specimens it is observed an opposite effect, that is, the reduction of fatigue limit is more accentuated than the decrease of hardness. The decrease of hardness after heat treatment of polished specimens was only $3 \%$, that is, the effect of softening could explain the reduction of fatigue limit, only if the residual stresses introduced by grounding were compression, which is not in according with some results found in the literature. After several experiments, Sosa et al. (2007) found that in all tests, tensile residual stresses were resulted from grinding steel plates. Similar results were found by El-Axir (2002). However, Matsumoto et al. (1991) reported that it is possible to find compressive residual stresses after polishing. A compressive residual stress induced by grinding was found to improve fatigue life, according to Schwach and Guo (2006). Thus, it is not possible with these results to determine the real causes of decreasing fatigue limit in polished specimens.

Table 6. Hardness (HV) of specimens of AISI 4140 steel.

\begin{tabular}{cccc}
\hline & \multicolumn{2}{c}{ Hardness (HV) } & Change \\
\cline { 2 - 4 } Condition & Without Relief Stress & After Heat treatment & $(\%)$ \\
\hline Machined (2.3) & $256.7 \pm 33.9$ & $196.5 \pm 19.5$ & -23 \\
\hline Polished & $213.2 \pm 8.5$ & $207.7 \pm 8.9$ & -3 \\
\hline
\end{tabular}

\section{Conclusions}

This paper presents the influence of commercial cutting parameters during machining on fatigue limits of AISI 4140 steel. Fatigue rotating bending tests were performed on steel specimens with zero mean stress at room temperature. The fatigue limit decreases with increasing roughness parameters. The influence of cutting parameters on fatigue limits is lower than that on surface roughness. The relation between residual stresses, strain hardening and roughness surface plays a dominant role. Stress relief heat treatment causes an increase of fatigue limit of machined specimens 
with high roughness parameters and a decrease in polished specimens. The softening of both specimen types (polished and machined) caused by the heat treatment is not similar. The sharp increase of fatigue limit of machined specimens is due to elimination of residual stress, which overcome the effect of surface layer softening.

\section{Acknowledgements}

Financial support of this research was provided by the Fundação de Amparo à Pesquisa de Minas Gerais (FAPEMIG), with additional assistance from the CAPES and CNPq (Brasilian National Research Bureaus).

\section{References}

Abouelatta, O. B. and Mádl, J., 2001, "Surface Roughness prediction based on Cutting Parameters and Tool vibrations in Turning Operations", J. of Mat. Process. Techn., Vol. 118, No 1, pp. 269, 277.

Arola, D. and Williams, C. L., 2002, "Estimating the Fatigue

Concentration Factor of Machined Surfaces", Int. J. of Fatigue, Vol. 24, No. 9, pp. 923-930.

Bailey, J. A., Jeelani, S. and Becker, S. E., 1976, "Surface Integrity in the Machining of quenched and tempered AISI 4340 Steel", ASME, J. Engng Ind., Vol. 98, pp. 999-1004.

Becker, R., 1998, "Effects of Strain localization on Surface Roughening during Sheet Forming", Acta Mater., Vol. 46, pp. 1385-1401.

Benardos, P. G. and Vosniakos, G. -C., 2003, "Predicting Surface Roughness in Machining: A review", Int. J. of Mach. Tools \& Manufacture, Vol. 43, No. 8, pp. 833-844.

Collins, J. A., 1993, "Failure of Materials in Mechanical Design Analysis Prediction and Prevention”, Ed. John Wiley \& Sons, Inc, New York, USA, 654p.

Davim, J. P., 2001, “A Note on the Determination of Optimal Cutting. Conditions for Surface Finish obtained in Turning using Design of Experiments", J. of Mater. Process. Techn. Vol. 116, pp. 305-308.

Du, B., Zhu, W., Ma, B. and Li, N., 2004, "Prolonging Fatigue Life of a Damaged Steel by Annealing", Int. J. of Fatigue, Vol. 26, No. 9, pp. 10171023.

El-Axir, M. H., 2002, “A Method of Modeling Residual Stress Distribution in Turning for different Materials", Int. J. of Mach. Tools \& Manufacture, Vol. 42, No. 9, pp. 1055-1063.

Feng, C-X., 2001, “An Experimental Study of the Impact of Turning Parameters on Surface Roughness", Proc. of the 2001 Industrial Engineering Research Conference, Institute of Industrial Engineers, Paper No. 2036, pp. 1-6.

Itoga, H., Tokaji, K., Nakajima, M. and Ko, H. -H., 2003, "Effect of Surface Roughness on Step-Wise S-N Characteristic in High Strength Steel", Int. J. of Fatigue, Vol. 25, No. 5, pp. 379-385.

Jang, D. Y. and Seireg, A., 1989, "Dynamic Simulation for Predicting Surface Roughness in Turning", ASME Machinery Dynamics-Applications and Vibration Control Problems, Vol. 18, pp. 31-36.
Jeelani, S. and Musial, M., 1984, "Effect of Cutting Speed and Tool Rake Angle on the Fatigue Life of 2024-T351 Aluminium Alloy", Int. J. of Fatigue, No.6, Vol. 6, pp. 169-172.

Koster, W., 1991, "Effect of Residual Stress on Fatigue of Structural Alloys", Proceedings of the Third International Conference, ASM International, Indianapolis, Indiana, USA, pp. 1-9.

Lee, Y. -L., Pan, J., Hathaway, R. and Barkey, M., 2005, "Fatigue Testing and Analysis - Theory and Practice", Ed. Elsevier Inc., Boston, USA, 312p..

Lin, S. -K., Lee, Y. -L. and Lu, M. -W., 2001, "Evaluation of the Staircase and the Accelerated Test Methods for Fatigue Limit Distributions", Int. J. of Fatigue, Vol. 23, No. 1, pp. 75-83.

Matsumoto, Y., Magda, D., Hoeppner, D. W. and Kim T. Y. 1991, "Effect of Machining Processes on the Fatigue Strength of hardened AISI Steel", J. Eng. Ind., Vol. 13, pp.154-159.

Nakajima, M., Tokaji, K., and Ko, H. -N., 2003, "Morphology of Stepwise S-N curves depending on Work-hardened layer and humidity in a Highstrength Steel", Fatigue Fract Engng Mater Struct, Vol.26, No. 12, pp. 11131118 .

Novovic, D., Dewes, R. C., Aspinwal, D. K., Voice, W. and Bowen, P., 2004, "The Effect of Machined Topography and Integrity on Fatigue Life", Int. J. of Mach. Tools \& Manufacture, Vol. 44, No. 2-3,pp. 125-134. Rech, J. and Moisan, A., 2003, "Surface Integrity in Finish Hard Turning of Case-Hardened Steels", Int. J. of Mach. Tools \& Manufacture, Vol. 43, No. 5, pp. 543-550.

Sasahara, H., 2005, "The effect on Fatigue Life of Residual Stress and Surface Hardness resulting from different Cutting Conditions of $0.45 \%$ Steel", Int. J. of Mach. Tools \& Manufacture, Vol. 45, No. 2, pp.131-136.

Schwach, D. W. and Guo, Y. B., 2006, "A Fundamental Study on the Impact of Surface Integrity by Hard Turning on rolling Contact Fatigue", Int. J. of Fatigue, Vol. 28, No. 12, pp. 1838-1844.

Sosa, A. D., Echeverria, M. D., Moncada, O. J. And Sikora, J. A., 2007, "Residual Stresses, Distortion and Surface Roughness produced by Grinding Thin Wall Ductile Iron Plates", Int. J. of Mach. Tools \& Manufacture, Vol. 47, No. 2, pp. 229-235.

Starkey, M. S. and Irving, P. E., 1982, “A Comparison of the Fatigue Strength of Machined and as-cast Surfaces of SG Iron", Int. J. of Fatigue, Vol. 4, No. 3, pp. 129-136.

Taylor, D. and Clancy, O. M., 1991, "The Fatigue Performance of Machined Surfaces", Fatigue Fract Engng Mater Struct, Vol. 14, pp. 329336.

Thomas, M. and Beauchamp, Y., 2003, "Statistical Investigation of Modal Parameters of Cutting Tools in Dry Turning”, Int. J. of Mach. Tools \& Manufacture, Vol. 43, No. 11, pp.1093-1106.

Trent, E. M. and Wright, P. K., 2000, "Metal Cutting", Ed. ButteworthsHeinemann Ltd., London, England, 446p.

Yang, W. and Tarng, Y., 1998, "Design Optimization of Cutting Parameters for Turning Operations based on Taguchi Method", J. Mater. Process. Technol., Vol. 84, pp.122-129.

Yue, Z. F., 2005, "Surface Roughness Evolution under Constant Amplitude Fatigue Loading using Crystal Plasticity”, Engng Fract. Mechanics, Vol. 72, pp. 749-757.

Zahavi, E. and Torbilo, V., 1996, "Fatigue Design: Life Expectancy of Machine Parts", Ed.: CRC Press, Boca Raton, Florida, USA, 354p. 